Int. J. Electrochem. Sci., 15 (2020) 10908 - 10921

International Journal of

ELECTROCHEMICAL

SCIENCE

www.electrochemsci.org

\title{
Prediction of Individual Ionic Activity Coefficients for Some Aqueous Chloride Salt Solutions
}

\author{
Li Sun ${ }^{1,2,3, *}$, Jierong Liang ${ }^{4}$ \\ ${ }^{1}$ Department of Chemical and Biochemical Engineering, Technical University of Denmark, 2800, Kgs. \\ Lyngby, Denmark \\ ${ }^{2}$ College of Mechanical and Electrical Engineering, Hohai University, Changzhou 213022, People's \\ Republic of China \\ ${ }^{3}$ School of Energy and Power Engineering, Wuhan University of Technology, Wuhan 430063, \\ People's Republic of China \\ ${ }^{4}$ Department of Energy Conversion and Storage, Technical University of Denmark, $2800 \mathrm{Kgs}$. \\ Lyngby, Denmark \\ *E-mail: 1sun@kt.dtu.dk; ORCID: 0000-0002-8448-1651
}

doi: $10.20964 / 2020.11 .36$

Received: 1 August 2020 / Accepted: 9 September 2020 / Published: 30 September 2020

Theoretical calculations of individual ionic activity coefficients (IIAC) for four chlorine salts in aqueous solutions are presented. The IIAC are predicted first by using Debye-Hückel theory with different ion radii, and the results show a significant deviation from experimental data. IIAC are also predicted by using Debye-Hückel theory plus the Born equation, and the results show that the DebyeHückel theory plus Born equation can accurately predict the IIAC (for example, the average relative deviations between predicted values and experimental data for the activity coefficients of $\mathrm{Na}^{+}, \mathrm{Cl}^{-}$and $\mathrm{NaCl}$ are $0.6 \%, 1.7 \%$, and $0.9 \%$, respectively). In calculations, experimental liquid densities and relative static permittivity are used, and the ion-ion interaction and ion-water interaction contributions of the activity coefficients are analysed and discussed. The effects of ion size on electrostatic interaction calculations are further discussed.

Keywords: Individual Ionic Activity Coefficients; Aqueous Electrolyte Solution; Classical Solution Theory; Ion Radius

\section{$\underline{\text { FULL TEXT }}$}

(C) 2020 The Authors. Published by ESG (www.electrochemsci.org). This article is an open access article distributed under the terms and conditions of the Creative Commons Attribution license (http://creativecommons.org/licenses/by/4.0/). 